Buletin Ilmiah Math. Stat. dan Terapannya (Bimaster)

Volume 08, No. 2 (2019), hal $213-220$.

\title{
ANALISIS METODE NEWTON-RAPHSON GANDA ORDE KONVERGENSI EMPAT DALAM MENYELESAIKAN SISTEM PERSAMAAN NONLINEAR
}

\author{
Devitriani, Mariatul Kiftiah, Yudhi \\ INTISARI
}

\begin{abstract}
Sistem persamaan nonlinear merupakan kumpulan dari beberapa persamaan nonlinear. Metode yang sering digunakan untuk menyelesaikan sistem persamaan nonlinear salah satunya adalah metode numerik dalam bentuk metode iterasi yang menghasilkan penyelesaikan berupa nilai hampiran. Metode NewtonRaphson Ganda merupakan metode iterasi dua langkah yang digunakan untuk mencari akar-akar persamaan nonlinear dengan orde konvergensi empat. Tujuan penelitian ini adalah menganalisis metode Newton-Raphson Ganda orde konvergensi empat untuk menyelesaikan sistem persamaan nonlinear. Langkah-langkah untuk mencari solusi sistem persamaan nonlinear dengan menggunakan metode ini adalah mencari nilai $\boldsymbol{A}_{n}$ sebagai solusi dari iterasi ke-n dengan $\left\|\boldsymbol{E}_{n}\right\|<E_{\delta}$. Hasil penelitian menunjukkan bahwa metode tersebut dapat menyelesaikan sistem persamaan nonlinear dengan orde konvergensi empat.
\end{abstract}

Kata Kunci: Metode Iterasi Dua Langkah, Metode Newton-Raphson, Orde Konvergensi

\section{PENDAHULUAN}

Metode numerik adalah teknik yang digunakan untuk memformulasikan masalah matematika sehingga dapat dipecahkan dengan operasi perhitungan biasa seperti tambah, kurang, kali, dan bagi [1]. Pada metode numerik, terdapat metode-metode untuk mencari solusi dari suatu persamaan, yaitu metode tertutup dan metode terbuka. Metode tertutup meliputi metode grafis, metode bagi-dua, dan metode posisi palsu, sedangkan metode terbuka meliputi iterasi titik tetap, akar ganda, metode Brent metode Secant dan metode Newton-Raphson [2]. Metode Newton-Raphson digunakan untuk mencari hampiran atau pendekatan terhadap akar fungsi real pada persamaan nonlinear. Penentuan akar-akar persamaan merupakan salah satu persoalan yang terdapat dalam persamaan nonlinear. Suatu persamaan dikatakan nonlinear jika suatu persamaan yang memiliki derajat atau variabelnya lebih dari satu yang berbentuk $f(x)=0$ dengan $f: D \subset \mathbb{R} \rightarrow \mathbb{R}$ adalah fungsi real yang terdefinisi pada interval terbuka $D[3]$.

Sistem persamaan nonlinear merupakan kumpulan dari beberapa persamaan nonlinear. Metode yang sering digunakan untuk menyelesaikan sistem persamaan nonlinear dimana persamaan tersebut tidak bisa diselesaikan secara analitik adalah dengan metode numerik dalam bentuk metode iterasi yang menghasilkan penyelesaikan berupa nilai hampiran. Metode iterasi yang digunakan pada penelitian ini adalah metode Newton-Raphson Ganda orde konvergensi empat.

Penelitian ini bertujuan untuk menganalisis metode Newton-Raphson Ganda orde konvergensi empat untuk menyelesaikan sistem persamaan nonlinear. Nilai galat tolerasi $\left(E_{\delta}\right)$ yang digunakan untuk menentukan solusi dari sistem persamaan nonlinear adalah $10^{-15}$ dan tingkat ketelitian 15 angka di belakang koma sebagai pemberhentian iterasi.

Langkah-langkah yang dilakukan dalam penelitian ini adalah diberikan suatu sistem persamaan nonlinear dengan titik awal $\left(\mathbf{A}_{\mathbf{0}}\right)$. Setelah itu lakukan iterasi pertama yaitu menentukan nilai $\mathbf{A}_{\mathbf{1}}$. Pada iterasi pertama tentukan nilai $\mathbf{F}\left(\mathbf{A}_{\mathbf{0}}\right)$ dan $\mathbf{J}\left(\mathbf{A}_{\mathbf{0}}\right)$, kemudian mencari nilai $\mathbf{B}_{\mathbf{0}}$ jika invers dari $\mathbf{J}\left(\mathbf{A}_{\mathbf{0}}\right)$ ada . Setelah mendapatkan nilai $\mathbf{B}_{\mathbf{0}}$ selanjutnya tentukan nilai $\mathbf{F}\left(\mathbf{B}_{\mathbf{0}}\right)$ dan $\mathbf{J}\left(\mathbf{B}_{\mathbf{0}}\right)$, untuk mendapatkan nilai $\mathbf{A}_{\mathbf{1}}$ jika invers dari $\mathbf{J}\left(\mathbf{B}_{\mathbf{0}}\right)$ ada. Selanjutnya menentukan nilai norm galat pertama, ketika nilai norm galat pertama lebih kecil dari galat toleransi yang diberikan maka iterasi sudah selesai dan $\mathbf{A}_{\mathbf{1}}$ merupakan solusi dari sistem persamaan nonlinear. Tetapi ketika nilai norm galat pertama lebih besar atau sama dengan galat tolerasi yang diberikan, maka perlu dilakukan iterasi selanjutnya sampai memperoleh nilaigalat yang lebih kecil galat toleransi yang diberikan. Nilai $\mathbf{A}_{\mathbf{n}}$ yang diperoleh dari hasil iterasi merupakan solusi dari sistem persamaan nonlinear. 


\section{PERSAMAAN NONLINEAR DAN SISTEM PERSAMAAN NONLINEAR}

Suatu persamaan dikatakan nonlinear jika suatu persamaan yang memiliki derajat atau variabelnya lebih dari satu misalkan kuadrat, kubik, trigonometri atau dalam bentuk lainnya. Sistem persamaan nonlinear merupakan kumpulan dari beberapa persamaan nonlinear. Bentuk umum sistem persamaan nonlinear dapat ditulis sebagai berikut:

$$
\begin{gathered}
f_{1}\left(x_{1}, x_{2}, \ldots, x_{n}\right)=0 \\
f_{2}\left(x_{1}, x_{2}, \ldots, x_{n}\right)=0 \\
\vdots \\
f_{n}\left(x_{1}, x_{2}, \ldots, x_{n}\right)=0
\end{gathered}
$$

dengan fungsi $f_{i} ; i=1,2, \ldots, n$ merupakan fungsi yang memetakan dari $\mathbb{R}^{n}$ ke $\mathbb{R}$. Sistem persamaan nonlinear juga dapat direpresentasikan dengan mendefinisikan fungsi $\mathbf{F}$, pemetaan $\mathbb{R}^{n}$ ke $\mathbb{R}^{n}$ sebagai berikut:

$$
\mathbf{F}\left(x_{1}, x_{2}, \ldots, x_{n}\right)=\left(f_{1}\left(x_{1}, x_{2}, \ldots, x_{n}\right), f_{2}\left(x_{1}, x_{2}, \ldots, x_{n}\right), \ldots, f_{n}\left(x_{1}, x_{2}, \ldots, x_{n}\right)\right)^{T} .
$$

Jika variabel $\mathbf{X}=\left(x_{1}, x_{2}, \ldots, x_{n}\right)$ merupakan suatu vektor yang digunakan untuk menjelaskan sistem Persamaan (1) maka persamaan tersebut dapat ditulis dengan bentuk sebagai berikut:

$$
\mathbf{F}(\mathbf{X})=\mathbf{0} \text {. }
$$

Fungsi $f_{1}, f_{2}, \ldots, f_{n}$ disebut dengan koordinat fungsi dari $\mathbf{F}$ [4].

\section{METODE NEWTON-RAPHSON}

Metode Newton-Raphson digunakan untuk mencari hampiran atau pendekatan terhadap akar fungsi real. Rumus metode Newton-Raphson sebagai berikut:

$$
x_{n}=x_{n-1}-\frac{f\left(x_{n-1}\right)}{f^{\prime}\left(x_{n-1}\right)}, f^{\prime}\left(x_{n-1}\right) \neq 0 .
$$

adapun algoritma metode Newton-Raphson sebagai berikut:

1. Tentukan persamaan nonlinear yang akan dicari solusi persamaannya.

2. Tentukan iterasi maksimum epsilon $\left(\varepsilon_{\delta}\right)$ sebagai toleransi kesalahan.

3. Tentukan titik awal $x_{0}$.

4. Hitung $f\left(x_{0}\right)$ dan $f^{\prime}\left(x_{0}\right)$.

5. Hitung $x_{n}=x_{0}-\frac{f\left(x_{0}\right)}{f^{\prime}\left(x_{0}\right)} ; f^{\prime}\left(x_{0}\right) \neq 0, n=1,2,3, \ldots$

6. Jika $\left|x_{n}-x_{n-1}\right|<\varepsilon_{\delta}$, atau iterasi lebih besar atau sama dengan iterasi maksimum tulis $x_{\text {hampiran }}=x_{n}$, jika tidak lanjut ke langkah selanjutnya.

7. Ganti nilai $x_{0}=x_{n}$ dan kembali ke langkah 4 .

Metode Newton-Raphson merupakan metode iterasi yang memiliki konvergensi kuadratik [1]. Persamaan galat metode Newton-Raphson adalah sebagai berikut:

$$
\left|e_{n}\right|=\left|\frac{f^{\prime \prime}(p)}{2 f^{\prime}(p)}\right| e_{n-1}^{2}+O\left(e_{n-1}^{3}\right)
$$

dengan $p$ merupakan akar dari $f(x)$ dan $n=1,2,3, \ldots[5]$.

\section{METODE NEWTON-RAPHSON GANDA}

Metode Newton-Raphson Ganda merupakan salah satu metode iterasi yang digunakan untuk menentukan akar-akar persamaan nonlinear dengan orde konvergensi empat. Pada penelitian ini untuk menurunkan metode Newton-Raphson Ganda digunakan pendekatan secara geometri yang dapat dilihat pada Gambar 1. 


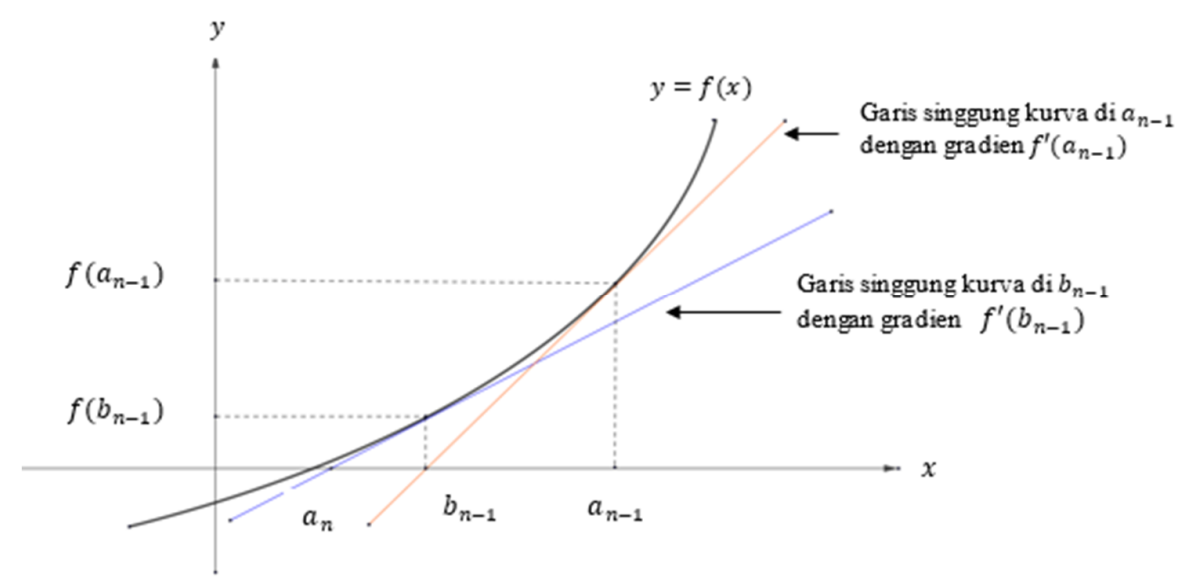

Gambar 1. Tafsiran Geometri Metode Newton-Raphson Ganda

Berdasarkan Gambar 1, garis singgung kurva di $a_{n-1}$, dengan gradien garis singgungnya adalah

atau

$$
m=f^{\prime}\left(a_{n-1}\right)=\frac{\Delta y}{\Delta x}=\frac{f\left(a_{n-1}\right)-0}{a_{n-1}-b_{n-1}}
$$

$$
f^{\prime}\left(a_{n-1}\right)=\frac{f\left(a_{n-1}\right)}{a_{n-1}-b_{n-1}}
$$

sedangkan untuk garis singgung kurva di $b_{n-1}$, dengan gradien garis singgungnya adalah

$$
m=f^{\prime}\left(b_{n-1}\right)=\frac{\Delta y}{\Delta x}=\frac{f\left(b_{n-1}\right)-0}{b_{n-1}-a_{n}}
$$

atau

$$
f^{\prime}\left(b_{n-1}\right)=\frac{f\left(b_{n-1}\right)}{b_{n-1}-a_{n}}
$$

Berdasarkan Persamaan (2) dan (3) maka diperoleh rumus metode Newton-Raphson Ganda sebagai berikut:

$$
\begin{gathered}
b_{n-1}=a_{n-1}-\frac{f\left(a_{n-1}\right)}{f^{\prime}\left(a_{n-1}\right)}, \quad f^{\prime}\left(a_{n-1}\right) \neq 0 \\
a_{n}=b_{n-1}-\frac{f\left(b_{n-1}\right)}{f^{\prime}\left(b_{n-1}\right)}, \quad f^{\prime}\left(b_{n-1}\right) \neq 0
\end{gathered}
$$

Pada persamaan nonlinear $f(x)=0$, metode Newton-Raphson memerlukan turunan dari fungsi $f(x)$ yaitu $f^{\prime}(x)$ untuk setiap iterasinya. Sedangkan untuk menyelesaikan persoalan persamaan yang lebih dari satu atau sistem persamaan nonlinear $\mathbf{F}(\mathbf{X})=\mathbf{0}$ metode Newton-Raphson memerlukan matriks Jacobian $\mathbf{J}(\mathbf{X})$ untuk setiap iterasinya. Matriks Jacobian tersebut digunakan sebagai pengganti turunan fungsi $\mathbf{F}(\mathbf{X})$ atau dalam matematika ditulis $\mathbf{F}^{\prime}(\mathbf{X})$, dengan syarat matriks $\mathbf{J}(\mathbf{X})$ adalah matriks nonsingular. Rumus metode Newton-Raphson untuk menyelesaikan sistem persamaan nonlinear sebagai berikut:

$$
X_{n}=X_{n-1}-J^{-1}\left(X_{n-1}\right) F\left(X_{n-1}\right)
$$

Berdasarkan Persamaan (5) diperoleh rumus metode Newton-Raphson Ganda untuk menyelesaikan sistem persamaan nonlinear sebagai berikut:

$$
\begin{aligned}
B_{n-1} & =A_{n-1}-J^{-1}\left(A_{n-1}\right) F\left(A_{n-1}\right) \\
A_{n} & =B_{n-1}-J^{-1}\left(B_{n-1}\right) F\left(B_{n-1}\right)
\end{aligned}
$$

\section{ANALISIS KONVERGENSI}

Berikut teorema yang memberikan tingkat kesalahan dari Persamaan (6) yang menunjukkan orde konvergensi. 
Teorema 1. Misalkan F: $D \subset \mathbb{R}^{n} \rightarrow \mathbb{R}^{n}$ fungsi yang mempunyai turunan pada interval $D$. Misalkan juga $\mathbf{F}$ mempunyai akar sederhana $\boldsymbol{\alpha} \epsilon D$. Jika diberikan nilai awal $\mathbf{A}_{\mathbf{0}}$ cukup dekat ke $\boldsymbol{\alpha}$ maka metode iterasi Persamaan (6) mempunyai orde konvergensi empat dan memenuhi persamaan galat:

$$
\begin{aligned}
& \mathbf{E}_{\mathbf{n}}=\mathbf{C}_{2}^{*} \mathbf{C}_{2}^{2} \mathbf{E}_{\mathbf{n}-1}^{\mathbf{4}}+\mathbf{O}\left(\left\|\mathbf{E}_{\mathbf{n}-1}^{5}\right\|\right) \\
& \text { dengan } \mathbf{C}_{\mathbf{j}}=\frac{\mathbf{F}^{\prime}\left(\mathbf{A}_{\mathbf{n}-\mathbf{1}}\right)^{-\mathbf{1}} \mathbf{F}^{(\mathbf{j})}\left(\mathbf{A}_{\mathbf{n}-\mathbf{1}}\right)}{\mathbf{j} !} \operatorname{dan} \mathbf{C}_{\mathbf{j}}^{*}=\frac{\mathbf{F}^{\prime}\left(\mathbf{B}_{\mathbf{n}-\mathbf{1}}\right)^{-\mathbf{1}} \mathbf{F}^{(\mathbf{j})}\left(\mathbf{B}_{\mathbf{n}-\mathbf{1}}\right)}{\mathbf{j} !}, j \geq 1 \text { dan } \mathbf{E}_{\mathbf{n}-\mathbf{1}}=\mathbf{A}_{\mathbf{n}-\mathbf{1}}-\boldsymbol{\alpha} \text {. }
\end{aligned}
$$

Bukti: Misalkan $\boldsymbol{\alpha} \in D$ dimana $\boldsymbol{\alpha}$ merupakan akar dari $\mathbf{F}(\mathbf{A})$, maka $\mathbf{F}(\boldsymbol{\alpha})=\mathbf{0}$ dan $\mathbf{F}^{\prime}(\boldsymbol{\alpha})$ merupakan matriks nonsingular. Deret Taylor dari $\mathbf{F}(\mathbf{A})$ disekitar $\mathbf{A}=\mathbf{A}_{\mathbf{n}-\mathbf{1}}$ sebagai berikut:

$$
\mathbf{F}(\mathbf{A})=\mathbf{F}\left(\mathbf{A}_{\mathbf{n}-1}\right)+\mathbf{F}^{\prime}\left(\mathbf{A}_{\mathbf{n}-1}\right)\left(\mathbf{A}-\mathbf{A}_{\mathbf{n}-1}\right)+\frac{1}{2 !} \mathbf{F}^{\prime \prime}\left(\mathbf{A}_{\mathbf{n}-1}\right)\left(\mathbf{A}-\mathbf{A}_{\mathbf{n}-1}\right)^{2}+\frac{1}{3 !} \mathbf{F}^{\prime \prime \prime}\left(\mathbf{A}_{\mathbf{n}-1}\right)\left(\mathbf{A}-\mathbf{A}_{\mathbf{n}-1}\right)^{3}+\cdots
$$

karena $\boldsymbol{\alpha}$ merupakan akar dari $\mathbf{F}(\mathbf{A})$, maka $\mathbf{F}(\boldsymbol{\alpha})=\mathbf{0}$ sehingga diperoleh:

$$
\mathbf{F}\left(\mathbf{A}_{n-1}\right)=\mathbf{F}^{\prime}\left(\mathbf{A}_{n-1}\right)\left(\mathbf{A}_{n-1}-\alpha\right)-\frac{1}{2 !} \mathbf{F}^{\prime \prime}\left(\mathbf{A}_{n-1}\right)\left(\mathbf{A}_{n-1}-\boldsymbol{\alpha}\right)^{2}+\frac{1}{3 !} \mathbf{F}^{\prime \prime \prime}\left(\mathbf{A}_{n-1}\right)\left(\mathbf{A}_{n-1}-\boldsymbol{\alpha}\right)^{3}-\cdots
$$

pada Persamaan (7) kedua ruas dikalikan dengan $\mathbf{F}^{\prime}\left(\mathbf{A}_{\mathbf{n}-\mathbf{1}}\right)^{-\mathbf{1}}$ diperoleh:

$$
\begin{aligned}
A_{n-1}-F^{\prime}\left(A_{n-1}\right)^{-1} \mathbf{F}\left(A_{n-1}\right)= & \\
& \alpha+\frac{1}{2 !} F^{\prime}\left(A_{n-1}\right)^{-1} F^{\prime \prime}\left(A_{n-1}\right)\left(A_{n-1}-\alpha\right)^{2}- \\
& \frac{1}{3 !} F^{\prime}\left(A_{n-1}\right)^{-1} F^{\prime \prime \prime}\left(A_{n-1}\right)\left(A_{n-1}-\alpha\right)^{3}+\cdots \\
B_{n-1}= & \alpha+C_{2} E_{n-1}^{2}-C_{3} E_{n-1}^{3}+\cdots \\
B_{n-1}-\alpha= & C_{2} E_{n-1}^{2}-C_{3} E_{n-1}^{3}+\cdots
\end{aligned}
$$

selanjutnya akan dicari $\mathbf{F}^{\prime}\left(\mathbf{B}_{\mathbf{n}-\mathbf{1}}\right)^{-\mathbf{1}} \mathbf{F}\left(\mathbf{B}_{\mathbf{n}-\mathbf{1}}\right)$ dengan menggunakan deret Taylor dari $\mathbf{F}(\mathbf{B})$ disekitar $\mathbf{B}=\mathbf{B}_{\mathbf{n}-\mathbf{1}}$ sebagai berikut:

$$
\mathbf{F}(\mathbf{B})=\mathbf{F}\left(\mathbf{B}_{\mathbf{n}-1}\right)+\mathbf{F}^{\prime}\left(\mathbf{B}_{\mathbf{n}-1}\right)\left(\mathbf{B}-\mathbf{B}_{\mathbf{n}-1}\right)+\frac{1}{2 !} \mathbf{F}^{\prime \prime}\left(\mathbf{B}_{\mathbf{n}-1}\right)\left(\mathbf{B}-\mathbf{B}_{\mathbf{n}-1}\right)^{2}+\ldots
$$

karena $\boldsymbol{\alpha}$ merupakan akar dari $\mathbf{F}(\mathbf{B})$, maka $\mathbf{F}(\boldsymbol{\alpha})=\mathbf{0}$ sehingga diperoleh:

$\mathbf{F}\left(\mathbf{B}_{\mathbf{n}-1}\right)=\mathbf{F}^{\prime}\left(\mathbf{B}_{\mathbf{n}-1}\right)\left(\mathbf{B}_{\mathbf{n}-1}-\boldsymbol{\alpha}\right)-\frac{1}{2 !} \mathbf{F}^{\prime \prime}\left(\mathbf{B}_{\mathbf{n}-1}\right)\left(\mathbf{B}_{\mathbf{n}-1}-\boldsymbol{\alpha}\right)^{2}+\cdots$

pada Persamaan (10) kedua ruas dikalikan dengan $\mathbf{F}^{\prime}\left(\mathbf{B}_{\mathbf{n}-\mathbf{1}}\right)^{\mathbf{- 1}}$ diperoleh:

$\mathbf{F}^{\prime}\left(\mathbf{B}_{\mathbf{n}-\mathbf{1}}\right)^{-1} \mathbf{F}\left(\mathbf{B}_{\mathbf{n}-1}\right)=\left(\mathbf{B}_{\mathbf{n}-\mathbf{1}}-\boldsymbol{\alpha}\right)-\mathbf{C}_{2}^{*}\left(\mathbf{B}_{\mathbf{n}-\mathbf{1}}-\boldsymbol{\alpha}\right)^{2}+\cdots$

substitusikan Persamaan (9) ke Persamaan (12) sehingga diperoleh:

$F^{\prime}\left(B_{n-1}\right)^{-1} F\left(B_{n-1}\right)=C_{2} E_{n-1}^{2}-C_{3} E_{n-1}^{3}+\ldots-C_{2}^{*} C_{2}^{2} E_{n-1}^{4}+C_{2}^{*} C_{2} C_{3} E_{n-1}^{5}-\cdots$

substitusikan Persamaan (8) dan (13) ke persamaan berikut ini:

$$
\begin{aligned}
& A_{\mathbf{n}}=B_{n-1}-F^{\prime}\left(B_{n-1}\right)^{-1} \mathbf{F}\left(B_{n-1}\right) \\
& =\alpha+C_{2}^{*} C_{2}^{2} E_{n-1}^{4}-C_{2}^{*} C_{2} C_{3} E_{n-1}^{5}+\cdots \\
& A_{n}-\alpha=C_{2}^{*} C_{2}^{2} E_{n-1}^{4}-C_{2}^{*} C_{2} C_{3} E_{n-1}^{5}+\cdots \\
& E_{n}=C_{2}^{*} C_{2}^{2} E_{n-1}^{4}+\mathbf{O}\left(\left\|E_{n-1}^{5}\right\|\right)
\end{aligned}
$$

Jadi, terbukti bahwa Persamaan (6) memiliki orde konvergensi empat.

\section{SIMULASI NUMERIK}

Pada simulasi numerik ini diberikan contoh sebagai berikut:

Contoh 1. $\mathbf{F}_{\mathbf{1}}(\mathbf{A})=\left\{\begin{array}{l}f_{1}(x, y)=x^{2}-10 x+y^{2}+8 \\ f_{2}(x, y)=x y^{2}+x-10 y+8\end{array}\right.$

dengan nilai awal $\left(x_{0}, y_{0}\right)=(2,2)$ akan ditentukan penyelesaian dari Persamaan (14).

\section{Penyelesaian:}

Menentukan nilai iterasi pertama $\left(\mathbf{A}_{\mathbf{1}}\right)$ pada Persamaan (14) dengan metode Newton-Raphson Ganda adalah sebagai berikut:

Adapun langkah-langkah yang dilakukan yaitu:

Iterasi pertama 
1) Nilai $\mathbf{A}_{\mathbf{0}}=\left[\begin{array}{l}2 \\ 2\end{array}\right]$ disubstitusikan ke dalam Persamaan (14) untuk mendapatkan nilai $\mathbf{F}\left(\mathbf{A}_{\mathbf{0}}\right)$, sebagai berikut:

$$
\begin{aligned}
\mathbf{F}\left(\mathbf{A}_{\mathbf{0}}\right) & =\left[\begin{array}{c}
2^{2}-10(2)+2^{2}+8 \\
2(2)^{2}+2-10(2)+8
\end{array}\right] \\
& =\left[\begin{array}{l}
-4 \\
-2
\end{array}\right]
\end{aligned}
$$

2) Mencari $\mathbf{J}\left(\mathbf{A}_{\mathbf{0}}\right)$ pada Persamaan (14) dengan mensubstitusikan nilai $\mathbf{A}_{\mathbf{0}} \mathrm{ke} \mathbf{J}(\mathbf{A})$, sehingga diperoleh:

$$
\begin{aligned}
\mathbf{J}\left(\mathbf{A}_{\mathbf{0}}\right) & =\left[\begin{array}{cc}
2(2)-10 & 2(2) \\
2^{2}+1 & 2(2)(2)-10
\end{array}\right] \\
& =\left[\begin{array}{cc}
-6 & 4 \\
5 & -2
\end{array}\right]
\end{aligned}
$$

3) Setelah diperoleh nilai $\mathbf{J}\left(\mathbf{A}_{\mathbf{0}}\right)$, langkah selanjutnya yaitu mencari invers $\mathbf{J}\left(\mathbf{A}_{\mathbf{0}}\right)$, maka diperoleh: $\mathbf{J}^{-\mathbf{1}}\left(\mathbf{A}_{\mathbf{0}}\right)=\left[\begin{array}{cc}0,25 & 0,5 \\ 0,625 & 0,75\end{array}\right]$

4) Hasil $\mathbf{J}^{\mathbf{- 1}}\left(\mathbf{A}_{\mathbf{0}}\right)$ digunakan untuk mendapatkan nilai $\mathbf{B}_{\mathbf{0}}$, sehingga diperoleh:

$$
\begin{aligned}
\mathbf{B}_{\mathbf{0}} & =\mathbf{A}_{\mathbf{0}}-\mathbf{J}^{-\mathbf{1}}\left(\mathbf{A}_{\mathbf{0}}\right) \mathbf{F}\left(\mathbf{A}_{\mathbf{0}}\right) \\
& =\left[\begin{array}{l}
4 \\
6
\end{array}\right]
\end{aligned}
$$

5) Nilai $\mathbf{B}_{\mathbf{0}}=\left[\begin{array}{l}4 \\ 6\end{array}\right]$ disubstitusikan ke Persamaan (14) untuk mendapatkan nilai $\mathbf{F}\left(\mathbf{B}_{\mathbf{0}}\right)$, sebagai berikut:

$$
\begin{aligned}
\mathbf{F}\left(\mathbf{B}_{\mathbf{0}}\right) & =\left[\begin{array}{c}
4^{2}-10(4)+6^{2}+8 \\
2(6)^{2}+4-10(6)+8
\end{array}\right] \\
& =\left[\begin{array}{l}
20 \\
96
\end{array}\right]
\end{aligned}
$$

6) Nilai $\mathbf{B}_{\mathbf{0}}$ disubstitusikan ke $\mathbf{J}(\mathbf{A})$, sebagai berikut:

$$
\begin{aligned}
\mathbf{J}\left(\mathbf{B}_{\mathbf{0}}\right) & =\left[\begin{array}{cc}
2(4)-10 & 2(6) \\
6^{2}+1 & 2(4)(6)-10
\end{array}\right] \\
& =\left[\begin{array}{cc}
-2 & 12 \\
37 & 38
\end{array}\right]
\end{aligned}
$$

7) Setelah diperoleh nilai $\mathbf{J}\left(\mathbf{B}_{\mathbf{0}}\right)$, langkah selanjutnya yaitu mencari invers $\mathbf{J}\left(\mathbf{B}_{\mathbf{0}}\right)$, sebagai berikut:

$$
\mathbf{J}^{-\mathbf{1}}\left(\mathbf{B}_{\mathbf{0}}\right)=\left[\begin{array}{cl}
-0,073076923076923 & 0,023076923076923 \\
0,071153846153846 & 0,003846153846154
\end{array}\right]
$$

8) Hasil $\mathbf{J}^{\mathbf{- 1}}\left(\mathbf{B}_{\mathbf{0}}\right)$ digunakan untuk mendapatkan nilai $\mathbf{A}_{\mathbf{1}}$ sehingga iterasi pertama untuk Persamaan (14) diperoleh sebagai berikut:

$$
\begin{aligned}
\mathbf{A}_{\mathbf{1}} & =\mathbf{B}_{\mathbf{0}}-\mathbf{J}^{-\mathbf{1}}\left(\mathbf{B}_{\mathbf{0}}\right) \mathbf{F}\left(\mathbf{B}_{\mathbf{0}}\right) \\
& =\left[\begin{array}{l}
3,246153846153846 \\
4,207692307692308
\end{array}\right]
\end{aligned}
$$

Setelah diperoleh nilai $\mathbf{A}_{\mathbf{1}}$, langkah selanjutnya yaitu mencari nilai galat dari Persamaan (3.15). Pada penelitian ini galat ditentukan menggunakan galat iterasi dan norm galat.

1) Adapun galat iterasi sebagai berikut:

$$
\begin{aligned}
\mathbf{E}_{\mathbf{1}} & =\mathbf{A}_{\mathbf{1}}-\mathbf{A}_{\mathbf{0}} \\
& =\left[\begin{array}{l}
1,246153846153846 \\
2,207692307692308
\end{array}\right]
\end{aligned}
$$

2) Setelah galat iterasi diperoleh maka langkah selanjutnya adalah mencari nilai norm galat.

$$
\begin{aligned}
\left\|\mathbf{E}_{\mathbf{1}}\right\| & =\sqrt{\left(x_{1}-x_{0}\right)^{2}+\left(y_{1}-y_{0}\right)^{2}} \\
& =\sqrt{(1,246153846153846)^{2}+(2,207692307692308)^{2}}
\end{aligned}
$$




$$
=2,535114343324145
$$

karena nilai norm galat pertama $\left\|\mathbf{E}_{\mathbf{1}}\right\|>E_{\delta}$ maka iterasi dilanjutkan, untuk hasil dari iterasi kedua dan seterusnya dapat dilihat pada Tabel 1 berikut ini:

Tabel 1. Hasil Iterasi $\mathbf{F}_{\mathbf{1}}(\mathbf{A})$

\begin{tabular}{ccc}
\hline \multirow{2}{*}{ Iterasi ke- $n$} & \multicolumn{2}{c}{$\mathbf{A}_{\mathbf{n}}$} \\
\cline { 2 - 3 } & 3,246153846153846 & 4,207692307692308 \\
1 & 2,252347067217603 & 3,105414609155852 \\
2 & 2,193446781640577 & 3,020477560415579 \\
4 & 2,193439415415308 & 3,020466468123034 \\
5 & 2,193439415415308 & 3,020466468123034
\end{tabular}

Tabel 1 menunjukkan hasil semua iterasi dari solusi sistem persamaan nonlinear pada Persamaan (14) dengan iterasi sebanyak lima kali dengan solusi akhir yang didapat yaitu untuk $x=2,193439415415308$ dan $y=3,020466468123034$.

Tabel 2. Nilai Galat Iterasi dan Norm Galat $\mathbf{F}_{\mathbf{1}}(\mathbf{A})$

\begin{tabular}{ccc}
\hline$x_{n}-x_{n-1}$ & $y_{n}-y_{n-1}$ & $\left\|\mathbf{E}_{\mathbf{n}}\right\|$ \\
\hline 1,246153846153846 & 2,207692307692308 & 2,535114343324145 \\
$-0,993806778936243$ & $-1,102277698536456$ & 1,484138820511901 \\
$-0,058900285577026$ & $-0,084937048740273$ & 0,103361239784375 \\
$-0,000007366225269$ & $-0,000011092292545$ & 0,000013315404613 \\
0 & 0 & 0
\end{tabular}

Tabel 2 menunjukkan perhitungan galat pada iterasi $x_{n}=0$ dan galat pada iterasi $y_{n}=0$. Kedua galat iterasi tersebut digunakan untuk mendapatkan nilai $\left\|\mathbf{E}_{\mathbf{n}}\right\|$. Iterasi akan berhenti jika nilai $\left\|\mathbf{E}_{\mathbf{n}}\right\|$ kurang dari galat toleransi yang diberikan. Nilai awal $\mathbf{A}_{\mathbf{0}}$ pada Persamaan (14) iterasi norm galat berhenti pada iterasi kelima yaitu dengan nilai $\left\|\mathbf{E}_{\mathbf{n}}\right\|=0$.

Contoh $2 . \mathbf{F}_{\mathbf{2}}(\mathbf{A})=\left\{\begin{array}{l}f_{1}(x, y, z)=15 x+y^{2}-4 z-13 \\ f_{2}(x, y, z)=x^{2}+10 y-e^{-z}-11 \\ f_{3}(x, y, z)=y^{3}-25 z+22\end{array}\right.$

dengan nilai awal $\left(x_{0}, y_{0}, z_{0}\right)=(10,6,-5)$ akan ditentukan penyelesaian dari Persamaan (15).

\section{Penyelesaian:}

Dengan cara yang sama diperoleh hasil semua iterasi Persamaan (15) berikut ini:

Tabel 3. Hasil Iterasi $\mathbf{F}_{2}(\mathbf{A})$

\begin{tabular}{cccc}
\hline \multirow{2}{*}{ Iterasi ke- $n$} & \multicolumn{3}{c}{$\mathbf{A}_{\mathbf{n}}$} \\
\cline { 2 - 4 } & $x$ & $y$ & $z$ \\
\hline 1 & 1,191150060455799 & $-0,584520557593059$ & $-1,906978815813594$ \\
2 & 1,137789008039214 & 1,011806285374029 & 0,887369457790716 \\
3 & 1,042149588142102 & 1,031091270656041 & 0,923848053770065 \\
4 & 1,042149560576938 & 1,031091271839402 & 0,923848154879368 \\
5 & 1,042149560576938 & 1,031091271839402 & 0,923848154879368 \\
\hline
\end{tabular}


Tabel 3 menunjukkan hasil semua iterasi dari solusi sistem persamaan nonlinear pada Persamaan (15) dengan iterasi sebanyak lima kali dengan solusi akhir yang didapat yaitu untuk $x=1,042149560576938, y=1,031091271839402$ dan $z=0,923848154879368$.

Tabel 4. Nilai Galat Iterasi dan Norm Galat $\mathbf{F}_{2}(\mathbf{A})$

\begin{tabular}{cccc}
\hline$x_{n}-x_{n-1}$ & $y_{n}-y_{n-1}$ & $z_{n}-z_{n-1}$ & $\left\|\mathbf{E}_{\mathbf{n}}\right\|$ \\
\hline$-8,808849939544201$ & $-6,584520557593059$ & 3,093021184186406 & 11,424470590648802 \\
$-0,053361052416585$ & 1,596326842967088 & 2,794348273604310 & 3,218616017124077 \\
$-0,095639419897112$ & 0,019284985282012 & 0,036478595979349 & 0,104160920023817 \\
$-0,000000027565164$ & 0,000000001183361 & 0,000000101109303 & 0,000000104806153 \\
0 & 0 & 0 & 0 \\
\hline
\end{tabular}

Tabel 4 menunjukkan perhitungan galat pada iterasi $x_{n}=0$, galat pada iterasi $y_{n}=0$, dan galat pada iterasi $z_{n}=0$. Ketiga galat iterasi tersebut digunakan untuk mendapatkan nilai $\left\|\mathbf{E}_{\mathbf{n}}\right\|$. Iterasi akan berhenti jika nilai $\left\|\mathbf{E}_{\mathbf{n}}\right\|$ kurang dari galat toleransi yang diberikan. Nilai awal $\mathbf{A}_{\mathbf{0}}$ pada Persamaan (15) iterasi norm galat berhenti pada iterasi kelima yaitu dengan nilai $\left\|\mathbf{E}_{\mathbf{n}}\right\|=0$.

Contoh 3. $\mathbf{F}_{3}(\mathbf{A}): f_{i}=x_{i}^{2}-\cos \left(x_{i}-1\right), \quad i=1,2,3,4,5$

dengan nilai awal $\mathbf{A}_{\mathbf{0}}=(2,2,2,2,2)$, akan ditentukan penyelesaian dari Persamaan (15).

Penyelesaian:

Dengan cara yang sama diperoleh hasil semua iterasi Persamaan (15) berikut ini:

Tabel 5. Hasil Iterasi $\mathbf{F}_{\mathbf{3}}(\mathbf{A})$

\begin{tabular}{cccccc}
\hline & \multicolumn{5}{c}{$\mathbf{A}_{\mathbf{n}}$} \\
Iterasi ke- $n$ & $x_{1}$ & $x_{2}$ & $x_{3}$ & $x_{4}$ & $x_{5}$ \\
\cline { 2 - 6 } 1 & 1,042546364312057 & 1,042546364312057 & 1,042546364312057 & 1,042546364312057 & 1,042546364312057 \\
2 & 1,000001218825076 & 1,000001218825076 & 1,000001218825076 & 1,000001218825076 & 1,000001218825076 \\
3 & 1 & 1 & 1 & 1 & 1 \\
4 & 1 & 1 & 1 & 1 & 1 \\
\hline
\end{tabular}

Tabel 5 menunjukkan hasil semua iterasi dari solusi sistem persamaan nonlinear pada Persamaan (15) dengan iterasi sebanyak lima kali dengan solusi akhir yang didapat yaitu untuk $x_{1}=1, x_{2}=1, x_{3}=1, x_{4}=1$, dan $x_{5}=1$.

Tabel 6. Nilai Galat Iterasi dan Norm Galat $\mathbf{F}_{3}(\mathbf{A})$

\begin{tabular}{cccccc}
\hline$\left(x_{1}^{(n)}\right)-\left(x_{1}^{(n-1)}\right)$ & $\left(x_{2}^{(n)}\right)-\left(x_{2}^{(n-1)}\right)$ & $\left(x_{3}^{(n)}\right)-\left(x_{3}^{(n-1)}\right)$ & $\left(x_{4}^{(n)}\right)-\left(x_{4}^{(n-1)}\right)$ & $\left(x_{5}^{(n)}\right)-\left(x_{5}^{(n-1)}\right)$ & $\left\|\mathbf{E}_{\mathbf{n}}\right\|$ \\
\hline$-0,957453635687943$ & $-0,957453635687943$ & $-0,957453635687943$ & $-0,957453635687943$ & $-0,957453635687943$ & 2,140931414702560 \\
$-0,042545145486981$ & $-0,042545145486981$ & $-0,042545145486981$ & $-0,042545145486981$ & $-0,042545145486981$ & 0,095133837421506 \\
$-0,000001218825076$ & $-0,000001218825076$ & $-0,000001218825076$ & $-0,000001218825076$ & $-0,000001218825076$ & 0,000002725375723 \\
0 & 0 & 0 & 0 & 0 & 0
\end{tabular}

Tabel 6 menunjukkan perhitungan galat pada iterasi $\left(x_{1}^{(n)}\right)=0$, galat pada iterasi $\left(x_{2}^{(n)}\right)=0$, galat pada iterasi $\left(x_{3}^{(n)}\right)=0$, galat pada iterasi $\left(x_{4}^{(n)}\right)=0$, dan galat pada iterasi $\left(x_{5}^{(n)}\right)=0$. Kelima galat iterasi tersebut digunakan untuk mendapatkan nilai $\left\|\mathbf{E}_{\mathbf{n}}\right\|$. Iterasi akan berhenti jika nilai $\left\|\mathbf{E}_{\mathbf{n}}\right\|$ kurang 
dari galat toleransi yang diberikan. Nilai awal $\mathbf{A}_{\mathbf{0}}$ pada Persamaan (16) iterasi norm galat berhenti pada iterasi kelima yaitu dengan nilai $\left\|\mathbf{E}_{\mathbf{n}}\right\|=0$.

\section{PENUTUP}

Metode Newton-Raphson Ganda digunakan untuk menyelesaikan sistem persamaan nonlinear, dengan rumus:

$$
\begin{aligned}
B_{n-1} & =A_{n-1}-J^{-1}\left(A_{n-1}\right) F\left(A_{n-1}\right) \\
A_{n} & =B_{n-1}-J^{-1}\left(B_{n-1}\right) F\left(B_{n-1}\right)
\end{aligned}
$$

Hasil penelitian ini metode Newton-Raphson Ganda dengan orde kenvergensi empat dapat menyelesaikan sistem persamaan nonlinear. Adapun langkah-langkah dalam menyelesaikan sistem persamaan nonlinear dengan menggunakan metode Newton-Raphson Ganda adalah sebagai berikut:

1. Diberikan sistem persamaan nonlinear dengan titik awal $\mathbf{A}_{\mathbf{0}}$ dan $E_{\delta}$ sebagai galat toleransi.

2. Hitung $\mathbf{F}\left(\mathbf{A}_{\mathbf{0}}\right)$ dan $\mathbf{J}^{-\mathbf{1}}\left(\mathbf{A}_{\mathbf{0}}\right)$.

3. Hitung $\mathbf{B}_{\mathbf{n}-\mathbf{1}}=\mathbf{A}_{\mathbf{0}}-\mathbf{J}^{-\mathbf{1}}\left(\mathbf{A}_{\mathbf{0}}\right) \mathbf{F}\left(\mathbf{A}_{\mathbf{0}}\right),\left|\mathbf{J}\left(\mathbf{A}_{\mathbf{0}}\right)\right| \neq 0$

4. Hitung $\mathbf{F}\left(\mathbf{B}_{\mathbf{n}-\mathbf{1}}\right)$ dan $\mathbf{J}^{-\mathbf{1}}\left(\mathbf{B}_{\mathbf{n}-\mathbf{1}}\right)$.

5. Hitung $\mathbf{A}_{\mathbf{n}}=\mathbf{B}_{\mathbf{n}-\mathbf{1}}-\mathbf{J}^{-\mathbf{1}}\left(\mathbf{B}_{\mathbf{n}-\mathbf{1}}\right) \mathbf{F}\left(\mathbf{B}_{\mathbf{n}-\mathbf{1}}\right),\left|\mathbf{J}\left(\mathbf{B}_{\mathbf{n}-\mathbf{1}}\right)\right| \neq 0$

6. Jika $\left\|\mathbf{E}_{\mathbf{n}}\right\| \geq E_{\delta}$, maka lanjut ke langkah selanjutnya yaitu ganti nilai $\mathbf{A}_{\mathbf{0}}=\mathbf{A}_{\mathbf{n}}, n=1,2,3, \ldots$ dan kembali ke langkah 4 .

7. Jika $\left\|\mathbf{E}_{\mathbf{n}}\right\|<E_{\delta}$, maka diperoleh $\mathbf{A}_{\mathbf{n}}$ solusi dari sistem persamaan nonlinear.

\section{DAFTAR PUSTAKA}

[1] Munir R. Metode Numerik. Bandung: Informatika; 2015.

[2] Chapra SC, Canale RP. Numerical Methods for Engineers Ed ke-7. New York: McGraw-Hill Education; 2015.

[3] Muhaijir MN, Arif M. Metode Iterasi Orde Konvergensi Enam Untuk Penyelesaian Persamaan Nonlinear. Seminar Nasional Teknologi Informasi, Komunikasi dan Industri. 2017; ISSN: 24604542.

[4] Burden RL, Faires JD. Numerical Analysis Ed ke-9. USA: Boston, 2011.

[5] Mathews JH. Numerical Methods for Mathematics, Science, and Engineering Ed ke-2 New Jersey: Prentice-Hall; 1992.

DEVITRIANI

MARIATUL KIFTIAH

YUDHI
: Jurusan Matematika FMIPA Untan, Pontianak devitriani05@gmail.com

: Jurusan Matematika FMIPA Untan, Pontianak kiftiahmariatul@math.untan.ac.id

: Jurusan Matematika FMIPA Untan, Pontianak dhye_dhoank@yahoo.co.uk 